\title{
LETTER TO THE EDITOR APPLICATION OF INTERNATIONAL CLASSIFICATION OF FUNCTIONING, DISABILITY AND HEALTH (ICF), FUNCTIONAL HEALTH AND DISABILITY
}

\author{
Olga Švestková, Petra Sládková, Karla Kotková \\ Department of Rehabilitation Medicine, First Faculty of Medicine, Charles University, Prague, Czech Republic
}

\begin{abstract}
SUMMARY
The International Classification of Functioning, Disability and Health (ICF) is a common language for different professions in the health, social, educational and vocational systems for lawyers, decision makers and politicians. It deals with how to describe health conditions, functional health and disability. It gives detailed operational definitions of different functions that constitute health. From body function and body structure to activities of daily living and participation in society. ICF has brought international consensus on definitions and provided a framework to describe public health and disability.
\end{abstract}

Key words: health condition, disability, functional health, activity, participation, ICF, rehabilitation

Address for correspondence: 0 . Švestková, Department of Rehabilitation Medicine, First Faculty of Medicine, Charles University, Albertov 7 , 12808 Prague 2, Czech Republic. E-mail: olga.svestkova@|f1.cuni.cz

http://dx.doi.org/10.21101/cejph.a4140

\section{INTRODUCTION}

The definition of rehabilitation of the World Health Organization (WHO) (1) is: the combined and coordinated use of medical, social, educational and vocational measures for training or retraining the individual to the highest possible level of functional ability.

The aspect of classification of functional abilities and expression of the level of disability in disabled persons is not only a professional, but also a political issue.

The concept of disability is becoming an increasingly important problem with the development of modern medicine, which is frequently capable of combating clinical death and is able to treat very serious, formerly fatal disorders of the human organism. In the past thirty years, the limitation of functions and structures has become very important. These limited functions and restricted participation can be compensated by undisturbed functions and participation or facilitators of environmental factors. It is one of the basic pillars of the International Classification of Functioning, Disability and Health (ICF) of the World Health Organization $(1,2)$.

\section{Disability and Legal Issues}

It has been found that disability is evaluated differently in the different countries of the world. In November 2007 at a conference in Milan, in the 6th framework of the EU Measuring Health and Disability in Europe: Supporting Policy Development - MHADIE (3), the European Commission, the Organization for Economic Cooperation and Development (OECD), representatives of the
World Health Organization, the United Nations Organization (UN), and representatives of other European organizations of citizens with disabilities agreed that ICF would be used as a basic methodology for evaluating the functional abilities of persons with disabilities.

The rights of disabled persons are increasingly becoming part of the legislation. This is reflected in both European legislation and in the adoption of the UN Convention on the Rights of Persons with Disabilities $(4,5)$, in which the European Union actively participated.

The European Union and the other countries of the world need good-quality, reliable and comparable data. Without this data, it is impossible to understand and evaluate the development of the overall situation of disabled persons. From this point of view, ICF is of great importance, as it forms a conceptual framework permitting further developments in this area. Thanks to ICF, it is possible to better define and evaluate the positive or negative impacts of various aspects of the environment on the participation of persons with disability - how this environment mitigates the consequences of the disability (facilitation) or, on the other hand, how it aggravates the disability through the creation of new obstacles (barriers) $(6,7)$. The easier evaluation of these data, the greater the benefit and development of policy from the local, regional and national level up to the European level.

The UN Convention on the Rights of Persons with Disability (4) emphasizes the aspect of how the concept of disability should be defined. Some delegations at the meeting in New York were of the opinion that such a definition of disability or, at the very least, persons with a disability, is necessary. Disability, the defini- 
tion according to ICF, consensus of panel discussions in Prague: Disability is a decrement in the functioning of the body on an individual or social level that arises when an individual with a health condition encounters barriers in the environment (8).

The UN Convention on the Rights of Persons with Disabilities was signed by the representatives of 82 countries of the world, including the Czech Republic, on March 30, 2007. The Czech Republic ratified the Convention on Collection of International Agreements Nr. 10/ 2010, Item 4.

Article 26 - Habilitation and rehabilitation (the concept of habilitation is related to children and adolescents)

1. States Parties shall take effective and appropriate measures to enable persons with disabilities to attain and maintain maximum independence, full physical, mental, social and vocational ability, and full inclusion and participation in all aspects of life. To that end, States Parties shall organize, strengthen and extend comprehensive habilitation and rehabilitation services, particularly in the areas of health, employment, education and social services, in such a way that these services and programmes:

a) Begin at the earliest possible stage, and are based on the multidisciplinary assessment of individual needs and strengths; b) Support participation and inclusion in the community and all aspects of society, are voluntary, and are available to persons with disabilities as close as possible to their own communities, including in rural areas.

2. States Parties shall promote the development of initial and continuing training for professionals and staff working in habilitation and rehabilitation services.

3. States Parties shall promote the availability, knowledge and use of assistive devices and technologies, designed for persons with disabilities, as they relate to habilitation and rehabilitation. According to the newest UN information, approximately 10 percent of the world population suffers from disability, i.e. approximately 650 million persons, and their number is constantly increasing. People with disabilities thus constitute the most numerous minorities in the world.

\section{The Relationship between ICF and Disability}

A draft definition of disability was adopted in Prague in 2006 - entirely according to the International Classification of Functioning, Disability and Health (1). This definition corresponds to one of the fundamental standards that were also adopted by the Czech Republic, i.e. the "Standard Rules on Equalization of Opportunities for Persons with Disabilities. UN 1993" (5). There was a major philosophical shift in that ICF does not classify persons but describes and classifies the situations of every person under a series of circumstances related to health.

The benefits of the International Classification of Functioning, Disability and Health are as follows:

- Structure as a consequence of different policy definitions ("the aspect of unifying assessment of disability");

- Basis for policy inclusion;

- Basis for policy mobility;

- Harmony of relevance and coherence;

- Comparable data;

- Methodology can be evaluated.

We are of the opinion that the International Classification of Functioning, Disability and Health will become a flexible and meaningful instrument that can be employed for recording the incidence and prevalence of disabilities and, on this basis, services will be created and will be available in the social, education and employment domains with the goal of inclusion of people with disabilities and to achieve their optimal quality of live. It will enable the introduction of uniform evaluation of health and disability, comparable at a national and international level, and will clarify and unify the European system of data collection relating to persons with disabilities (9).

\section{Practical Application of ICF}

ICF can also be employed as a clinical instrument for evaluation, monitoring treatment under special conditions, vocational evaluation, rehabilitation in evaluating the functional abilities, capacity and performance of individuals, and in evaluating the outputs and success of rehabilitation, e.g., integration into the labour market, and for measuring outputs in the quality of life and environmental factors (10). It is also useful as a statistical instrument for collecting and recording data (prevalence and incidence of disability, in studies of the population, in research or management of information systems).

ICF can be employed in the system of nursing care, e.g. to create standards and, on this basis, to also finance these services, in the area of objective evaluation and definition of disability, in the area of ensuring objectivity of the need for technical aids (facilitating factor), and also in areas outside of health care, e.g. in insurance, social security, employment, education, economy, social policy, and in overall legislative development and in modification of the environment. ICF provides a description of the situation from the standpoint of the functional abilities of the person and their limitations and can be used as a framework for organizing this information. It structures information in a meaningful, mutually interconnected and readily accessible form $(10,11)$.

The number of persons with a disability is increasing as a consequence of progress in medicine. Even very serious cases can be treated. However, timely, individually tailored rehabilitation by an interprofessional team is required. According to WHO, 9 to $13 \%$ of the population of Europe suffers from disability. Thus the number of these people forms a "large minority in the population". It is not only ethical and moral, but also economically advantageous, as soon as possible, evaluate the functional abilities of patients following a disease, injury or congenital defect and, through rehabilitation, assist in reducing or alleviating their disability. If the disability continues, it is necessary to enable these people to live dignified lives and to include them optimally into society.

\section{Rehabilitation According to ICF Encompasses Three Basic Groups}

1. Body Function and Structure.

2. Projection to the level of the personality. In practice, the expression activity (evaluation of capacity) and its limits.

3. Participation (evaluation of performance) and factors of the environment (facilitators, barriers). The availability of various aids, legislation, the attitudes of other people, etc. Basically, this is a "disability situation" that the individual can deal with using his/her "functional health" $(6,9)$. 
This substantial change in the attitude towards rehabilitation is not currently greatly taken into account in assessing disability in the Czech Republic. Functional abilities are assessed on the basis of aetiological and morphological - functional changes at the level of the organs, but functional diagnosis of a person is very imperfect and the factor of the environment is practically not diagnosed. The system in the Czech Republic is fundamentally based on compensation for health disability and does not entail equalization of opportunity, i.e. equal opportunities for healthy persons and persons with disabilities (7).

We would like to point out the advantageousness of the use of the WHO International Classification for functional diagnosis and for evaluating participation, which is essential for patient/ clients inclusion. We would like to state the need for unification of functional diagnosis and assessment of participation according to international standards $(10,11)$.

Our common goals are inclusion of people with disabilities into society and support of their functional health.

\section{REFERENCES}

1. World Health Organization. ICF International classification of functioning, disability and health. Geneva: WHO; 2001.

2. Světová zdravotnická organizace. MKF Mezinárodní klasifikace funkčních schopností, disability a zdraví. Praha: Grada; 2008.

3. Measuring Health and Disability in Europe: Supporting Policy Development (MHADIE) 6th framework program EU SP24-CT-2004-513708,
2004-2008. Milan: Neurological Institute C. Besta IRCCS Foundation Milan; 2007.

4. Convention on the Rights of Persons with Disabilities. New York: United Nations; 2007.

5. Standard Rules on Equalization of Opportunities for Persons with Disabilities. New York: United Nations; 1993.

6. Eldar R, Kullmann L, Marincek C, Sekelj-Kauzlarič K, Švestková O, Palat M. Rehabilitation medicine in countries of Central/Eastern Europe. Disabil Rehabil. 2008;30(2):134-41.

7. Švestková O. Conceptual framework for rehabilitation in the Czech Republic: a proposal. Disabil Rehabil. 2002 Oct 15;24(15):798-801.

8. Leonardi M, Bickenbach J, Ustun TB, Kostanjsek N, Chatterji S MHADIE Consortium. The definition of disability: what is in a name? Lancet. 2006 Oct 7;368(9543):1219-21.

9. Švestková O. The importance of the International Classification of functioning, disability and Health (ICF). In: European Conference Rehabilitation - value for societies in Europe: conference book; 2014 October, 7-9; Warsaw, Poland. Warsaw: Ministerstwo Pracy i Polityki Spoledzne; 2014. p. 19-22. (In Polish.)

10. Goljar N, Burger H, Vidmar G, Leonardi M, Marincek C. Measuring patterns of disability using the International Classification of Functioning, Disability and Health in the post-acute stroke rehabilitation setting. J Rehabil Med. 2011 Jun;43(7):590-601.

11. Laxe S, Zasler N, Tschiesner U, López-Blazquez R, Tormos JM, Bernabeu M. ICF use to identify common problems on a TBI neurorehabilitation unit in Spain. NeuroRehabilitation. 2011;29(1):99-110.

Received October 22, 2014 Accepted in revised form November 10, 2015 